\title{
NOTES ON $\mathfrak{P}^{4}=$ BIBLIOTHÈQUE NATIONALE PARIS, SUPPLEMENTUM GRAECE $1120 / 5$
}

\section{Carsten Peter Thiede}

Philip W. Comfort's appeal ${ }^{1}$ for a palaeographical re-analysis of the Paris codex comparison with $\mathfrak{P}^{64}$ and $\mathfrak{P}^{67}$ was put into action when I had the opportunity to work with the original fragments in the manuscripts room of the Bibliothèque Nationale on February 22 and 23, 1995. The following is a brief summary of the most important and distinctive aspects to be gathered from $\mathfrak{P}^{4}$.

1) It should be noted that the fragments from Luke's gospel are not kept in box 2 of Supplement Gr. 1120, as is the impression given by most references to it, but in box 5 .

2) The fragment of a title page preserved with the other papyri in Suppl. Gr. 1120, 'EYAGGELION KATA MATHTHAION', which encouraged some scholars to believe that the Oxford/Barcelona Matthew may at one stage have belonged to the same codex, is written in a hand distinctly different from all three papyri; it is broader and wider, with a flat mu and markedly elongated upper horizontal strokes in the two gammas.

3) There can be no doubt that the material of the papyrus in $\mathfrak{P}^{4}$ and in $\$ p^{64} / \mathfrak{P}^{67}$ respectively is different. The dark brown of the Paris fragments, over against the light hue of the Oxford/Barcelona scraps, is organic and cannot be ascribed to different means of preservation and conservation. This

${ }^{1}$ See P.W. Comfort, 'Exploring the Common Identification of Three New Testament Manuscripts: $\mathfrak{P}^{4}, \mathfrak{P}^{64}$, and $\mathfrak{P}^{67^{\prime}}$, in TynB 46 (1995) 4354 . 
observation alone seems to exclude the possibility of the Paris fragment originally belonging to one and the same codex as the other two.

4) One of the striking features linking $\mathfrak{P}^{64}$ with $\mathfrak{P}^{67}$, the projection of a letter into the left margin in order to signify the first complete line of a new section which began in the preceding line ${ }^{2}$ is markedly different in $\mathfrak{P}^{4}$ : the Paris scribe always used two letters, rather than one, for this purpose. The photographs supplied in the first edition of $\mathfrak{P}^{4}$ are not very helpful, unfortunately, for any serious analysis, ${ }^{3}$ but even here, the unambiguous examples of ar/chomenos in fragment B, verso, Ire colonne, Lc III, 23 (planche IV) and of el/egen in fragment D, verso, Ire colonne, Lc V, 36 (planche VI) can be made out, pars pro toto. While this would not necessarily rule out the identicality of the scribes (any scribe might change his 'idiosyncracies' from time to time, perhaps even on behalf of a specific patron or customer), it would not happen within one and the same book; thus, it appears to rule out the identity of the codices.

5) The differences between the letters of $\mathfrak{P}^{64} / \mathfrak{P}^{67}$ and $\mathfrak{P}^{4}$ are less apparent and may be less significant than the similarities listed by Comfort. For example, the scribe of $\mathfrak{P}^{4}$ has a tendency to raise omega and omikron above the bottom line, but to keep his rho right on the line, much in fact like his tau, which in P $^{64}$ and P $^{67}$ extends underneath the bottom line in the same way as the upsilon, and which always has a straight top bar in $\mathfrak{P}^{4}$, but not always so in $\mathfrak{P}^{64} .^{4}$ Fragment $\mathrm{A}$, recto, of $\mathfrak{P}^{4}$ offers the clearest examples. In any case, the similarities would justify a closer analysis of the possibility that all three papyri were in fact written by the same person or at the same

\footnotetext{
2See my re-edition of $\mathfrak{P}^{64}$, 'Papyrus Magdalen Greek 17 (Gregory-Aland $\mathfrak{P}^{64}$ ): A Reappraisal', ZPE 105 (1995) 13-20, with plate, here at 20; reprinted above, TynB 46 (1995) 29-42, here at 42.

3J. Morell, 'Nouveaux fragments du papyrus 4', Revue Biblique 47 (1938) 5-22, planches I-VIII between 16 and 17.

${ }^{4}$ For the straight top bar of the tau, see Comfort, 'Three New Testament Manuscripts', 50.
} 
copying centre, using different styli, at different periods, and for different customers.

6) In my re-edition of $\$ p^{64}$, I was satisfied with the status quo as to the date of $\mathfrak{P}^{4}$, as the question of its date was, at the time, of no significance in the context of my paper. However, my work with the original fragments in Paris and the arguments provided by Comfort appear to me to point towards a date not much later than that of $\$ \$^{64} / \mathfrak{P} 67.5$

5See Comfort, 'Three New Testament Manuscripts', 51-3. 